\title{
Prevalence of Otitis Media with Effusion among Preschool Children in Port Harcourt, Nigeria
}

\author{
Chibuilke Nwosu, OB da Lilly-Tariah and Lucky Obukowho Onotai* \\ Department of ENT Surgery, University of Port Harcourt Teaching Hospital (UPTH), Nigeria
}

Submission: February 23, 2017; Published: March 06, 2017

*Corresponding author: Lucky Obukowho Onotai, Department of ENT Surgery, University of Port Harcourt Teaching Hospital (UPTH), Port Harcourt, Rivers State, Nigeria, Email: onotailuckinx@yahoo.co.uk

\begin{abstract}
Background: Otitis media with effusion (OME) is defined as inflammation of the middle ear with accumulation of non-purulent effusion or exudates within the middle ear. It is more common in young children, and it is the commonest cause of hearing loss in children worldwide. The aim of this study was to determine the prevalence of OME among children within the age of one to six years.

Methodology: This was a cross sectional study involving 226 preschool pupils selected by multi-staged sampling technique from ten (10) day-care and nursery schools from Port Harcourt metropolis, carried out between November 2014 and June 2015. The pupils had satisfied the inclusion and exclusion criteria. Tympanometry was done on each participant. Type B and C tympanograms were the indicators of OME. Data was collected and analyzed using SPSS version-20.
\end{abstract}

Results: Among the 226 pupils, 57 had OME, giving a prevalence of $25.2 \%$. Thirty one (54.4\%) out of the 57 pupils, had unilateral OME while $26(45.6 \%)$ had bilateral OME. The peak age prevalence for OME was at the age of 2 years.

Conclusion: This study has shown a high prevalence of OME, thus making it a common disease among the preschool age group with the peak age of occurrence being at the age of two years. Therefore, parents/ guardians and teachers should be educated on early detection of hearing loss in a child such as poor response to call which could indicate presence of OME.

Keywords: Prevalence; Tympanometry; Otitis media with effusion (OME); School children

\section{Introduction}

Otitis media with effusion (OME) is defined as inflammation of the middle ear with accumulation of non-purulent effusion or exudates either mucous or serous fluid within the middle ear $[1,2]$. Various terms have been used to describe OME, among which are: Secretory otitis media, Serous otitis media, Middle ear effusion, and "glue ear" [1,2]. The disease has been reported to show some racial bias, being commoner among the Caucasians especially Canadians, Australian aboriginals and Native American children compared with Africans [3]. It is more common in infants and young children, and it is the commonest cause of hearing loss in children worldwide [2].

Otitis media with effusion is more common between the age of 1 to 6 years with Peak incidence occurring at the age of 2 years [1]. More than $50 \%$ of children will experience OME in their first year of life and by age of 10 years, $80 \%$ of children would have had one or more episode of OME [3]. It has a bimodal age distribution with the first and largest peak occurring at the age of 2 years at a prevalence of approximately $20 \%$ [1]. This peak occurs more during the stage of play group or nursery school attendance. Thereafter, the prevalence declines [1]. The second peak occurs at the age of 5 years with prevalence of about $16 \%$ when most children start attending a primary school [1].

Otitis media with effusion occurs most often during the first few years of life, a time that is critical for early language development [4]. The hearing loss associated with OME impedes children's ability to process language, thus compromising early childhood development [5]. Children with prolonged or frequent OME are said to have delays in their comprehension and production of language, attention problems and academic difficulties in school $[4,6]$. Over the years there has been notable significant morbidity associated with OME, probably due to poverty, ignorance, dearth of specialists and limited access to medical care [7]. Inadequate specialized health personnel and facilities poses problem as the Ear, nose and throat (ENT) trained personnel in our environment are still not enough to provide adequate ENT health care in both the rural and urban areas [8].

However, with adequate health education, availability of diagnostic facilities and trained personnel in our environment, 
there will be an improvement in the diagnosis of OME and therefore reduce the morbidity associated with OME, which will enhance their social well-being [8]. There is paucity of study on the prevalence of OME in the Niger Delta sub-region of Nigeria which is characterized by high rainfall and humidity, and also with high industrial activity [9], thus necessitating this study. The aim of this study was to determine the prevalence of OME among preschool children within the age of 1 to 6 years in Port Harcourt. It will also serve as a basis in the estimation of the prevalence of hearing loss in children as OME is the commonest cause of hearing loss in children.

\section{Methodology}

This was a prospective cross sectional study carried out among preschool children in Port Harcourt Metropolis. It was carried out between November 2014 and march 2015. The study included public and private daycare and nursery school children within the ages of 1-6 years. Those excluded are children with history or features of ear diseases, tympanic membrane perforation, previous ear surgery, congenital ear deformities. The minimum sample size estimation was 226 pupils.

A multi-staged sampling technique was employed: using simple random sampling, 10 schools were selected; using population proportion to size to assign number of pupils to each school; then using stratified sampling to select the pupils. Ethical clearance was given by our institution (UPTH) and informed consent was taken from the parents/guardian of all recruited pupils. A complete ENT and physical examination was carried out for all pupils. Tympanometry was done using Auto Tymp 262 Welch Allyn, USA. Types B and C were used as indicator of OME. The data was collected and analyzed using SPSS version 20. P < 0.05 was considered significant and confidence interval was set at $95 \%$.

\section{Results}

A total of 226 school pupils met the inclusion criteria and participated in the study. There were 130 (57.5\%) males and 96 $(42.5 \%)$ females. The mean age of the school pupils was 3.04 $( \pm 0.1)$, that for males was $3.04( \pm 1.6)$ and female $3.07( \pm 1.4)$. Occupying the highest proportion (20.8\%) were those aged 2 years, this is as shown in (Table 1). The prevalence of OME among the school pupils was $25.2 \%$ (57), This is as shown in (Table 2). The peak age prevalence of OME among the school pupils was 2 years (36.2\%), followed by 1 year (31.1\%), 3 years

Table 5: Types of Tympanograms in the ears. $(n=226)$

\begin{tabular}{|c|c|c|c|c|c|c|}
\hline \multirow{2}{*}{$\begin{array}{c}\text { Tympanograms } \\
\text { Type }\end{array}$} & \multicolumn{2}{|c|}{ Right Ear } & \multicolumn{2}{|c|}{ Left Ear } & \multicolumn{2}{|c|}{ Total Both ear } \\
\hline & Frequency & $\%$ & Frequency & $\%$ & Frequency & $\%$ \\
\hline A & 174 & 77.0 & 180 & 79.6 & 354 & 78.3 \\
\hline As & 8 & 3.5 & 7 & 3.1 & 15 & 3.3 \\
\hline Ad & 0 & 0 & 0 & 0 & 0 & 0 \\
\hline $\mathrm{B}$ & 14 & 6.2 & 11 & 4.9 & 25 & 5.5 \\
\hline
\end{tabular}

(23.9\%), 4 years $(20.5 \%), 5$ years $(16.7 \%), 6$ years $(7.1 \%)$. This is as shown in (Table 3) and (Figure 1). There was $31(54.4 \%)$ unilateral and $26(45.6 \%)$ bilateral OME out of the 57 pupils with ME (shown in Table 4). Fifty eight (12.8\%) of the ears had type ympanogram while type B was $25(5.5 \%)$, this is as shown in Table 5. Pupils within the Pre-Nursery (1-2 years) age group were shown to be statistically significant with the occurrence of OME $(\mathrm{p}<0.05)$. This is shown in Table 6.

Table 1: Age distribution of the school pupils. $(n=226)$

\begin{tabular}{|c|c|c|}
\hline Age (years) & Number of pupils & Percentage \\
\hline 1 & 45 & 19.9 \\
\hline 2 & 47 & 20.8 \\
\hline 3 & 46 & 20.4 \\
\hline 4 & 44 & 19.5 \\
\hline 5 & 30 & 13.3 \\
\hline 6 & 14 & 6.2 \\
\hline Total & 226 & 100.0 \\
\hline
\end{tabular}

Table 2: Prevalence of OME.

\begin{tabular}{|c|c|c|}
\hline & Frequency & Percentage (\%) \\
\hline OME & & \\
\hline No OME & 57 & 25.2 \\
\hline & 169 & 74.8 \\
\hline Total & & \\
\hline & 226 & 100 \\
\hline
\end{tabular}

Table 3: Peak age prevalence of OME. $(n=226)$

\begin{tabular}{|c|c|c|}
\hline Age (years) & Frequency & Percentage (\%) \\
\hline 1 & 14 & 31.1 \\
\hline 2 & 17 & 36.2 \\
\hline 3 & 11 & 23.9 \\
\hline 4 & 9 & 20.5 \\
\hline 5 & 5 & 16.7 \\
\hline 6 & 1 & 7.1 \\
\hline Total & 57 & 25.2 \\
\hline
\end{tabular}

Table 4: Laterality of OME among pupils with OME. $(n=226)$

\begin{tabular}{|c|c|c|}
\hline & Frequency & Percentage (\%) \\
\hline Unilateral OME & 31 & 54.4 \\
\hline Bilateral OME & 26 & 45.6 \\
\hline Total & & \\
\hline & 57 & 100 \\
\hline
\end{tabular}


Global Journal of Otolaryngology

\begin{tabular}{|c|c|c|c|c|c|c|}
\hline C & 30 & 13.3 & 28 & 12.4 & 58 & 12.8 \\
\hline Total & 226 & 100 & 226 & 100 & 452 & 100 \\
\hline
\end{tabular}

Table 6: Association between OME and Pre-Nursery (1-2 years) age group. $n=226$

\begin{tabular}{|c|c|c|c|c|c|c|}
\hline Variable & $\begin{array}{c}\text { OME } \\
\mathbf{N} \%\end{array}$ & $\begin{array}{c}\text { No OME } \\
\mathbf{N} \%\end{array}$ & $\begin{array}{c}\text { Total } \\
\mathbf{N}\end{array}$ & $\mathbf{X}^{2}$ & df & \\
\hline $\begin{array}{c}\text { Age category } \\
\text { Pre-Nursery (1-2 } \\
\text { years) }\end{array}$ & $31(33.7)$ & $61(61.3)$ & 92 & 5.908 & 1 \\
$\begin{array}{c}\text { Nursery (3-6 } \\
\text { years) }\end{array}$ & $26(19.4)$ & $108(80.6)$ & 134 & & $0.015^{*}$ \\
\hline
\end{tabular}

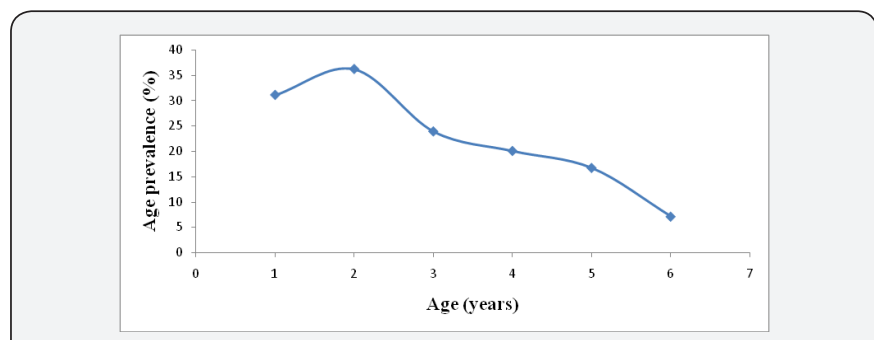

Figure 1: Peak age prevalence of OME.

\section{Discussion}

The prevalence of OME in this study was $25.2 \%$. This shows that approximately 1 in every 4 children within the age of 1 and 6 years have OME in Port Harcourt metropolis. This is not surprising as this work was done in Port Harcourt, an oil producing and industrialized area with high environmental pollution, high rainfall and humidity [9]. These factors are known to increase the susceptibility to acquiring OME [3]. This study shows higher prevalence when compared with a study done by Okolugbo and Ugwu [10] in 2009 with a reported prevalence of $15.9 \%$ among school children in Benin City aged 5-7 years. This relatively lower prevalence may probably be due to the lower industrial activity and lower environmental pollution when compared with Port Harcourt.

The work also did not capture the preschool age group known to be of higher risk of the disease [1]. Moreover, an earlier study in Benin City [11] reported a much lower prevalence of $8 \%$ among school children aged 5-6 years. A study done in Lagos [12] reported a prevalence of $18.2 \%$ among young children aged 2-7 years. This similarity may be due to the fact that the study captured the preschool age group and also it was done in a similar highly industrialized and highly polluted area with high humidity and rainfall. However, a much earlier study done in Lagos [13] reported a low prevalence of $4.9 \%$ among school entrance pupils aged 3-11 years. This low prevalence when compared to this study, may be due to the inclusion of older children and probably a relative lower environmental pollution recorded over 30 years ago when the study was done.

A recent work by Amusa et al. [14] in Ile-ife reported a very low prevalence of $<1 \%$ in a household random study of children
$<12$ years of age. This shows a very huge difference in prevalence when compared with the index study. The difference probably may be due to the wider age range of children involved and the geographical nature of Ile-Ife of lower humidity and rainfall and also lower environmental pollution [9]. The study design may also be a contributing factor as children were randomly selected from their homes compared to the school based study used in this study.

The prevalence rate in this study using only Type B tympanogram was $5.5 \%$ and Type $\mathrm{C} 12.8 \%$. This report is similar to the findings reported in Benin City [15] with reported prevalence rate for Type B, $6.7 \%$ and Type $\mathrm{C}, 9.2 \%$. These findings show a high prevalence of negative middle ear pressure relative to effusion among children with OME, thus reinforcing the importance of Eustachian tube dysfunction in the pathogenesis of OME. Studies in other developing countries appear to show a similar correlation with findings in this study. The study in Johannesburg [16] among children 2-16 years attending primary health center, reported a prevalence of $16.5 \%$ while in Malaysia [17], 18.3\% was reported among children visiting tertiary health center. The similarity in reports may be due to the relatively similar level of industrialization and resultant environmental pollution seen among the developing countries.

Reports in developed countries are relatively higher than the developing countries probably due to high level of industrialization and high humidity being experienced. Joanne et al. [18] reported a higher prevalence rate of $30.4 \%$ when compared with this study among American children in the United States between the ages of 6 months and 5 years in a community based child health program. This relative difference in the prevalence rate of OME may suggest that Africans may have a better functioning Eustachian tube; however there is little scientific evidence to support this [13]. Hence, the need for future research in evaluating this relative racial difference in the functioning of the Eustachian tube.

The peak age prevalence was found to be the age of 2 years with a prevalence of $36.2 \%$. There was an initial rise in prevalence from the age of 1 year and peak at 2 years, then a progressive decline with an increasing age to 6 years of age at a prevalence of $1.7 \%$. Also, the association between OME and 
combine ages of 1-2 years was statistically significant. This indicates a faster rate of normalization of the OME after the age of 2 years. The development of the Eustachian tube and the level of maturity of the immune system may explain this. This study was comparable with the results obtained among young African American children [19] with peak occurrence at 24-30 months of age and a decline in prevalence with increasing age to the age of 60 months. Also, similar peak age prevalence $(87 \%)$ at 2 years was reported during a serial tympanometric screening among preschool children in the Netherlands [20]. This shows a high prevalence of the disease among the Pre-nursery age group which coincide with the period when they are preparing to enter the Nursery school age. Freemantle et al. [21] reported a double peak prevalence rate (20\%) at both 2 and 6 years of age which is in contrast to the single peak obtained in this study. The second peak coinciding with the time pupils start attending primary schools.

This study shows significant association of the disease (OME) among the age group 1-2 years $(p<0.05)$. This shows that the younger age group is more prone to OME, probably because of their being more susceptible to infections and perhaps, the orientation of the Eustachian tube: being wider and shorter; with reduced cartilage density when compared with older children, making it too floppy and less stiffer which makes the Eustachian tube not to open properly during the contraction of the tensor veli palatini muscle [22]. This positive correlation further explains the peak prevalence at the age of 2 years reported in this study. In a cohort study among day-care facilities attendants in Lagos [23], there was a similar significant association between this age group and OME.

\section{Conclusion}

This study has shown a high prevalence of OME, thus making it a common disease among the preschool age group with the peak age of occurrence being at the age of two years. It also reported that the pre-nursery (1-2 years) age group is an important predictor of OME.

\section{Recommendation}

a) There should be continuous education of the parents and preschool teachers on early detection of hearing loss in a child which could indicate the presence of OME so as to prevent the sequelae that may arise.

b) Government should make policies on pre-admission and periodic hearing evaluation and tympanometric testing at least once yearly on preschool pupils.

\section{References}

1. Browning GG (2008) Otitis media with effusion. In: Gleeson M et al Eds.). Scott-Brown's Otolaryngology Head and Neck Surgery. ( $7^{\text {th }}$ edn). Vol 1, Arnold, London, UK, 877-885.

2. Haggard MP, Cannon MM, Birkin JA (2007) Otitis media with effusion
In: Anil L, (Ed.) Current diagnosis and treatment Otolaryngology-Head and Neck Surgery. ( ${ }^{\text {nd }}$ edn). Graw-Hill, New York, USA.

3. Margaret AK, Adriane DL (2006) Epidemiology of otitis media with effusion. In: Byron JB, et al. (Eds.). Head and Neck SurgeryOtolaryngology. ( $4^{\text {th }}$ edn). Vol 1. Williams and wilkins, New York, USA, 1297-1306.

4. Roberts JE, Burchinal MR, Jackson SC, Hooper SR, Roush J, et al. (2000) Otitis media in early childhood in relation to preschool language and school readiness skills among black children. Pediatrics 106(4): 725735 .

5. Somefun OA, Lesi FE, Danfulani MA, Olusanya BO (2006) Communication disorders in Nigerian children. Int J Pediatr Otorhinolaryngol 70(4): 697-702.

6. Pelton SI (1996) New concepts in the pathophysiology and management of middle ear disease in children. Drugs 52(2): 62-67.

7. Ibekwe T, Nwaorgu OG (2011) Classification and Management challenges of Otitis Media in a resource poor country. Niger J Clin Pract 14(3): 262-269.

8. Abdulazeez OA, Emmanuel SK, Emmanuel RA, Kehinde KO (2012) An appraisal of common otologic disorders as seen in a deaf population in North-Western Nigeria. Ann Afr Med 11(3): 153-156.

9. National Bureau of statistics (2010) Annual rainfall/relative humidity in Nigeria by States. Annual abstract of statistics 2010. Abuja: National Bureau of statistics.

10. Okolugbo NE, Ugwu M (2009) Prevalence of secretory otitis media among primary school children in benin city, Nigeria. Continental J Medical Research 3: 12-15.

11. Ogisi FO (1988) Impedance screening for Otitis media with effusion in Nigerian children. J laryngol Otol 102(11): 986-988.

12. Nwawolo CC, Akinlade O, Okeowo PA (1998) Tympanometric screening for OME in Nigerian children aged 2-7years. Nig Qt J Hosp Med 8(1): 44-46.

13. Okeowo PA (1985) Observations on the incidence of OME in Nigerian children. J Trop Pediatrics 31(6): 295-298.

14. Amusa YB, Ijaduola GTA, Onayade $O O$ (2005) Epidemiology of Otitis media in a local tropical African population. West Afr J Med 24(3): 227 230.

15. Olusanya BO, Okolo AA, Ijaduola GT (2000) The hearing profile of Nigerian school children. Int J Pediatr Otorhinolaryngol 55(3): 173178.

16. Biagio L, Swanepoel DW, Laurent C, Lungberg T (2014) Pediatric Otitis media at a Primary health care clinic in South Africa. S Afr Med J 104(6): 431-435.

17. Tikaram A, Chew YK, Zulkiflee AB, Chong AW, Prepageran N (2012) Prevalence and risk factors associated with OME in children visiting tertiary care center in Malaysia. International Medical Journal Malaysia 11(1): $37-40$

18. Roberts JE, Burchinal MR, Jackson SC, Hooper SR, Roush J, et al. (2000) Otitis media in early childhood in relation to preschool language and school readiness skills among black children. Pediatrics 106(4): 725735 .

19. Susan A, Joanne R, Eloise N, Rhoda R, Frederick H (1999) Longitudinal study of OME among 2-5year old African American children in child care. Pediatrics 103(1): 15-19.

20. Zielhuis GA, Rach GH, Van Den Broek P (1990) The occurrence of OME in Dutch preschool children. Clinical Otolaryngology 15(2): 147-153. 
21. Freemantle N, Sheldon TA, Song F (1992) The treatment of persistent glue ear in children: Are surgical interventions effective in combating disability from glue ear? Effective Health Care 4: 1-16.

22. Yamaguchi N, Sando I, Hashida Y (1990) Histological study of Eustachian tube cartilage with and without congenital anomaly: A preliminary study. Ann Otol Rhinol Laryngol 99(12): 984-987.
23. Asoegwu CN, Nwawolo CC, Somefun AO (2013) Prospective evaluation of the impact of Daycare attendance on the prevalence of OME in 6 to 24 months old children in urban Nigeria. Nig Q J Hosp Med 23(1): 7-11.

\section{Your next submission with Juniper Publishers} will reach you the below assets

- Quality Editorial service

- Swift Peer Review

- Reprints availability

- E-prints Service

- Manuscript Podcast for convenient understanding

- Global attainment for your research

- Manuscript accessibility in different formats ( Pdf, E-pub, Full Text, Audio)

- Unceasing customer service

Track the below URL for one-step submission https://juniperpublishers.com/online-submission.php 